\title{
Healthcare workers as parents: attitudes toward vaccinating their children against pandemic influenza $\mathrm{A} / \mathrm{H} 1 \mathrm{~N} 1$
}

Sebahat D Torun ${ }^{1 *}$, Fuat Torun², Binali Catak ${ }^{3}$

\begin{abstract}
Background: Both the health care workers (HCWs) and children are target groups for pandemic influenza vaccination. The coverage of the target populations is an important determinant for impact of mass vaccination. The objective of this study is to determine the attitudes of HCWs as parents, toward vaccinating their children with pandemic influenza A/H1N1 vaccine.

Methods: A cross-sectional questionnaire survey was conducted with health care workers (HCWs) in a public hospital during December 2009 in Istanbul. All persons employed in the hospital with or without a health-care occupation are accepted as HCW. The HCWs who are parents of children 6 months to 18 years of age were included in the study. Pearson's chi-square test and logistic regression analysis was applied for the statistical analyses.
\end{abstract}

Results: A total of $389 \mathrm{HCWs}$ who were parents of children aged 6 months-18 years participated study. Among all participants $27.0 \%(n=105)$ reported that themselves had been vaccinated against pandemic influenza A/H1N1. Two third (66.1\%) of the parents answered that they will not vaccinate their children, $21.1 \%$ already vaccinated and $12.9 \%$ were still undecided. Concern about side effect was most reported reason among who had been not vaccinated their children and among undecided parents. The second reason for refusing the pandemic vaccine was concerns efficacy of the vaccine. Media was the only source of information about pandemic influenza in nearly one third of HCWs. Agreement with vaccine safety, self receipt of pandemic influenza A/H1N1 vaccine, and trust in Ministry of Health were found to be associated with the positive attitude toward vaccinating their children against pandemic influenza A/H1N1.

Conclusions: Persuading parents to accept a new vaccine seems not be easy even if they are HCWs. In order to overcome the barriers among HCWs related to pandemic vaccines, determination of their misinformation, attitudes and behaviors regarding the pandemic influenza vaccination is necessary. Efforts for orienting the HCWs to use evidence based scientific sources, rather than the media for information should be considered by the authorities.

\section{Background}

Pandemic influenza A/H1N1 virus causes disease in all age groups, but it affects children stronger than adults in terms of attack rate and disease severity [1-3]. A study from United States reports that children were twice as susceptible to infection with the $2009 \mathrm{H} 1 \mathrm{~N} 1$ virus from a household member as adults 19 to 50 years of age [4]. Nearly $30 \%$ of the first reported cases of

\footnotetext{
* Correspondence: sdtorun@yahoo.com

${ }^{1}$ Assistt Rehberlik ve Müsteri Hizmetleri A.S., Istanbul, Turkey

Full list of author information is available at the end of the article
}

pandemic influenza A/H1N1 in Turkey have involved persons who were 18 years of age or younger [5].

The social contact network, and the way people interact within, is critical to the spread of influenza [6]. Children are under greater risk for influenza infection because they experience a large number of extra-household contacts with their peers in daycare centers or schools and some of the most intense outbreaks have been associated with schools [7-9].

Healthcare workers have increased risk of getting infected with influenza during outbreaks because they are exposed to infected individuals in the community as
() Biomed Central

C 2010 Torun et al; licensee BioMed Central Ltd. This is an Open Access article distributed under the terms of the Creative Commons Attribution License (http://creativecommons.org/licenses/by/2.0), which permits unrestricted use, distribution, and reproduction in any medium, provided the original work is properly cited. 
well as hospitalized patients with influenza. They may become an important reservoir of influenza virus for vulnerable patients under their care [10-12] and especially for the children in their household [13]. Being a child of a HCW parent theoretically will increase the risk of influenza infection of the child, although no quantitative information is available on the subject. On the other hand it is reported that family members with influenza, especially children, rather than the daily burden of influenza patients, make every General Practitioner, vaccinated or not, very vulnerable to infectious influenza [14]. The role of children as the main sources of influenza transmission within a community or household has been referred in many studies [15-17].

The most effective countermeasure against a pandemic virus will be a specific pandemic vaccine available for the whole population [18]. However the supply of vaccines will be limited at least during the beginning of the influenza pandemic. Therefore, prioritization in the administration of the limited vaccine supply has been one of the major components in pandemic preparedness. The World Health Organization (WHO) recommends that HCWs, children aged above 6 months with one of several chronic medical conditions and healthy children should be considered as priority groups for pandemic influenza $[19,20]$.

But influenza vaccine acceptance by HCWs is low even in the setting of pandemics [21-24].

Following the recommendations of the WHO, Turkish public health authorities have decided to start a mass vaccination campaign to mitigate the transmission of the pandemic influenza $A / H 1 N 1$. The $\mathrm{MoH}$ has purchased 8 million doses of pandemic vaccine. In the first phase of vaccination campaign, vaccination has been offered to health care providers, people between the ages of 6 months and 50 years with underlying conditions, healthy people between 6 months and 24 years of age, pregnant women and Haj pilgrims [25]. On November 2, 2009, the vaccination campaign started in the country and vaccination was free of charge [26]. Pandemic influenza vaccination was not mandatory. Mass vaccination of schoolchildren in schools has been planned to begin at December. Until that date parents could vaccinate their children in primary health care settings. Vaccination of children in schools depended on written parental consent. Because the ratio of parents who gave written consent for vaccination of their children in schools was very low all over the country, the $\mathrm{MoH}$ cancelled the mass vaccination in schools and schoolchildren continued to be vaccinated in primary health care settings [27].

The aim of this study was to examine the attitudes of hospital HCWs as parents of children aged 6 months to
18 years compliance with pandemic influenza $\mathrm{A} / \mathrm{H} 1 \mathrm{~N} 1$ vaccine during pandemic alert phase 6 in Istanbul.

\section{Methods \\ Study design and participants}

This study was conducted at Umraniye Research and Training Hospital (URTH), Istanbul, Turkey from 7-22 December 2009. The study hospital, hospital workforce and the population of the study have been reported elsewhere [24]. The participants of the previous reported study made up the study population of this study. Among all the 718 participants of the reported study, $389 \mathrm{HCW}$ met the inclusion criteria of being a parent of a child 6 month to 18 years of age.

\section{Data Collection}

Data was collected by a self- administered, anonymous questionnaire [Additional File 1] which the participants could complete in less than ten minutes. During the time when the previous study questionnaires were taken up, the questionnaire was delivered by hand directly to the participants and taken back by the second author who is one of the HCWs at the study hospital. The questionnaire consisted of questions regarding age, sex, marital status, occupation, years of work in health services, history of seasonal influenza vaccination in 2009 , source of knowledge for pandemic influenza, perception of risk and seriousness of pandemic influenza, agreement with pandemic vaccine safety and efficacy, confidence to Ministry of Health $(\mathrm{MoH})$ about pandemics, children 6 months to 5 years of age in the household, school children (6 to 18 years of age) in the household, whether respondents and their children are vaccinated with pandemic influenza $H 1 N 1$ vaccine and if not reasons for refusing pandemic influenza vaccine. Occupation was stratified into four groups based primarily upon education and training: (1) doctor, (2) nurse, (3) professional support staff and (4) nonprofessional support staff.

A brief oral and written description of the aim of the study was given to all the participants and verbal consent was obtained from the participants. Completed questionnaires were collected from the participants by the researchers within following days.

At time of our study was planned the activities of all the Research Ethic Committees (REC) were stopped in Turkey because the Turkish Medical Association has filed an action on 23 February 2009 requesting the cancellation of some of the provisions of the Regulation on the grounds that they are not in conformity with the international agreements in which Turkey is bound by [28]. Judicial order of the Council of State on 13.11.1009 with issue 2009/3991 E was motion for stay [29]. Authorization of 
our study is taken from Istanbul Provincial Directorate of Health.

\section{Statistics}

Data was analyzed by SPSS 10.0 version. Descriptive statistics were computed for the survey responses and demographic information. The main outcome variable was the parental attitude towards vaccinating their children against pandemic influenza A/H1N1 (vaccinated versus not vaccinated). By cross tabulations, we analyzed univariate associations between attitude towards vaccinating their children against pandemic influenza A/H1N1 and the following variables: sex, age, occupation, duration of employment in health care service, self-vaccination against pandemic influenza $\mathrm{A} / \mathrm{H} 1 \mathrm{~N} 1$ and receiving seasonal influenza vaccine in 2009, source of knowledge about pandemic influenza, how serious they thought is the pandemic, weather they trust to the information they receive from Ministry of Health $(\mathrm{MoH})$, agreement with pandemic vaccine safety and efficacy and agreement with some other statements related to pandemic. Pearson's Chi-square test was used for statistical analysis.

Univariate associations between child's pandemic influenza $\mathrm{A} / \mathrm{H} 1 \mathrm{~N} 1$ vaccination status and other variables were tested by logistic regression. All independent factors associated with the acceptance of pandemic influenza $\mathrm{A} / \mathrm{H} 1 \mathrm{~N} 1$ vaccination in cross tabulations were subsequently introduced in a backward multivariate logistic model. All of the analyses were two tailed, and $p$ values $<0.05$ considered as significant.

\section{Results}

Self- reported pandemic influenza $\mathrm{A} / \mathrm{H} 1 \mathrm{~N} 1$ vaccine receipt was not statistically different $(p>0.05)$ in HCWs who were parents of children 6 months- 18 years and the other interviewed HCWs (24.4\% and $20.6 \%$ respectively). Because the particular purpose of this report was to evaluate the attitudes of $\mathrm{HCW}$ s towards vaccinating their children with pandemic influenza $\mathrm{A} / \mathrm{H} 1 \mathrm{~N} 1$ vaccine, data of $389 \mathrm{HCWs}$ who have children aged 6 months-18 years, was further analyzed. Among 389 of HCWs 57.3\% were female; their mean age was $35.0 \pm 7.0$ years (range 20-56 years); median time of occupation in health care service 96.0 months (range 1- 420 months). Seventy seven percent of parents had children who were 6 month to 18 years of age, while $22.9 \%$ had children only children 6 month to 5 years of age. Doctors and nurses made up $50.1 \%(\mathrm{n}=195)$ of the respondents. Table 1 represents the characteristics of the participants and results of univariate analyzes. One-hundred and five $(27.0 \%)$ of the participants reported that themselves have been vaccinated against pandemic influenza A/H1N1. Among all parents $22.1 \%(n=82)$ already get vaccinated their children against pandemic influenza A/H1N1, 66.1\% ( $\mathrm{n}=$ 257) do not plan to get their children vaccinated and $12.9 \%(\mathrm{n}=50)$ were still undecided. Among parents who do not plan to get their children vaccinated against pandemic influenza $\mathrm{A} / \mathrm{H} 1 \mathrm{~N} 1$ or who were undecided about vaccination, the main reasons given for refusal were concerns about vaccine safety $(245 / 307,79.8 \%)$, or the respondents did not believe in efficacy of vaccination $(177 / 307,57.7 \%)$. Twenty one $(6.84 \%)$ parent reported their reason for refusing the vaccine as "just don't want to get vaccinate". Other reasons given for refusal of vaccination included because the child has had the seasonal influenza vaccination $(22 / 307,7.2 \%)$, “just don't want to get vaccinate the child" $(21 / 307,6.8 \%)$, and because the prime minister did not get the vaccine $(4 / 307)$.

The most reported source of information about pandemic influenza was media (television and newspaper) (83.0\%). Nearly one third of the participants (31.4\%) reported the media (television and newspapers) as their only source of information about pandemic influenza A/H1N1. The other most reported sources were Turkish Ministry of Health (49.6\%), colleagues/doctors (49.4\%), World Health Organization (13.6\%), educational seminars of local health authority of the city $(11.1 \%)$ and Centers for Disease Control and Prevention (3.1\%).

An important proportion (42.4\%) of the parents reported that did not trust in the declarations and suggestions of Turkish Ministry of Health $(\mathrm{MoH})$ about pandemic influenza. No association was found between trust in the $\mathrm{MoH}$ and occupation.

Univariate analysis showed that gender, occupation, parents' self vaccination against pandemic influenza, source of knowledge regarding pandemic influenza, agreement with pandemic vaccine safety, agreement with vaccine efficacy and trust in the declarations and suggestions of $\mathrm{MoH}$ were significantly associated with the parental attitude toward vaccinating their children against pandemic influenza A/H1N1 (Table 1).

Logistic regression analysis showed that agreement/ strong agreement with safety of the pandemic influenza vaccine $(\mathrm{OR}=2.351 ; 95 \% \mathrm{CI}: 1.116-4.953)$ and self receipt of pandemic influenza vaccine $(\mathrm{OR}=13.624$; 95\%CI: 7.140 - 25.993) were significantly associated with positive parental attitude to vaccinate their children with pandemic influenza vaccine (Table 2).

\section{Discussion}

Our study revealed a low (21.1\%) pandemic influenza A/H1N1 vaccination rate among children whose parents are healthcare workers. A study conducted in Italy at WHO pandemic alert phase 6 reports that $12.8 \%$ of mothers would have their children vaccinated, whereas 44.4\% would remain doubtful [30]. Although in our study, the vaccination rate among children whose 
Table 1 Characteristics of the respondents by attitude towards vaccinating their children (Values are percentages of respondents)

\begin{tabular}{|c|c|c|c|c|c|}
\hline \multirow[b]{2}{*}{ Characteristic of parents } & \multicolumn{5}{|c|}{ Attitude towards vaccinating their children } \\
\hline & $\begin{array}{c}\text { Total } \\
(\mathrm{N}=389)\end{array}$ & $\begin{array}{l}\text { Vaccinated } \\
(\mathrm{N}=82)\end{array}$ & $\begin{array}{l}\text { Not vaccinated } \\
(\mathrm{N}=257)\end{array}$ & $\begin{array}{l}\text { Undecided } \\
(\mathrm{N}=50)\end{array}$ & $\mathrm{p}$ value \\
\hline \multicolumn{6}{|l|}{ Gender } \\
\hline Female & 57.3 & 17.5 & 71.7 & 10.8 & 0.023 \\
\hline Male & 42.7 & 25.9 & 58.4 & 15.7 & \\
\hline \multicolumn{6}{|l|}{ Occupation } \\
\hline Doctor & 27.5 & 32.7 & 55.1 & 12.1 & 0.004 \\
\hline Nurse & 22.6 & 17.0 & 69.3 & 13.6 & \\
\hline Professional support staff & 11.8 & 15.2 & 60.9 & 23.9 & \\
\hline Nonprofessional support staff & 38.0 & 16.9 & 73.6 & 9.5 & \\
\hline \multicolumn{6}{|l|}{ Years of work in health services } \\
\hline$<5$ & 40.1 & 19.9 & 69.9 & 10.3 & 0.361 \\
\hline $5-9$ & 12.6 & 22.4 & 71.4 & 6.1 & \\
\hline $10-14$ & 15.7 & 21.3 & 63.9 & 14.8 & \\
\hline$\geq 15$ & 31.6 & 22.0 & 60.2 & 17.9 & \\
\hline \multicolumn{6}{|l|}{ Received pandemic influenza vaccine } \\
\hline Yes & 27.0 & 60.0 & 24.8 & 15.2 & $<0.000$ \\
\hline No & 73.0 & 6.7 & 81.3 & 12.0 & \\
\hline \multicolumn{6}{|l|}{ Sources of information* } \\
\hline WHO and/or CDC besides $\mathrm{MoH}$ & 13.6 & 37.7 & 52.8 & 9.4 & 0.003 \\
\hline $\mathrm{MoH}$ & 36.0 & 22.2 & 62.1 & 15.7 & \\
\hline Physicians (no any health authority) & 19.0 & 23.0 & 62.2 & 14.8 & \\
\hline Only media (television/newspaper) & 31.4 & 11.5 & 78.7 & 9.8 & \\
\hline \multicolumn{6}{|c|}{ Pandemic influenza $A / H 1 N 1$ vaccine is safe } \\
\hline Agree/strong agree & 48.6 & 36.0 & 46.6 & 17.4 & $<0.000$ \\
\hline Disagree & 55.6 & 7.0 & 84.5 & 8.5 & \\
\hline \multicolumn{6}{|c|}{ Vaccine is effective in preventing pandemic influenza } \\
\hline Agree/strong agree & 56.3 & 31.5 & 52.1 & 16.4 & $<0.000$ \\
\hline Disagree & 43.7 & 7.7 & 84.1 & 8.2 & \\
\hline \multicolumn{6}{|c|}{ Trust the declarations and suggestions of Ministry of Health } \\
\hline Yes & 57.6 & 29.5 & 56.2 & 14.3 & $<0.000$ \\
\hline No & 42.4 & 9.7 & 79.4 & 10.9 & \\
\hline
\end{tabular}

*MoH: Ministry of Health, WHO: World Health Organization, CDC: Centers for Disease Control and Prevention.

Table 2 Logistic Regression Analysis: Factors associated with vaccinating their children with pandemic influenza A/H1N1 vaccine

\begin{tabular}{lcc}
\hline Factors & Odds Ratio & $\mathbf{9 5 \%} \mathbf{C l}$ \\
\hline Self receipt of pandemic influenza vaccine & & $\mathbf{p}$ value \\
\hline Yes & 13.624 & $7.140-25.993$ \\
\hline No & 1 & {$[$ reference] } \\
\hline Agreement with pandemic influenza A/H1N1 vaccine safety & & \\
\hline Agree/strong agree & 2.351 & $1.116-4.953$ \\
\hline Disagree & 1 & {$[$ reference] } \\
\hline Trust in the declarations and suggestions of Ministry of Health & & 0.025 \\
\hline Yes & 1.885 & $0.917-3.874$ \\
\hline No & 1 & {$[$ reference] }
\end{tabular}


parents were doctor was higher (32.7\%) than the children whose parents were nurse or support staff, we can come to the conclusion that even doctors, who are the most educated HCWs, were resistant to vaccinating their children against pandemic influenza A/H1N1. A recent study reports high education of the parent, being a health care worker and perception of vaccine ineffectiveness as determinants of fully negative attitude towards vaccination [31].

Lack of confidence in the $\mathrm{MoH}$ among our study population was thought provoking. The no confidence probably can be explained with dissidence between the $\mathrm{MoH}$ as the main authority in the national pandemic plan and the Turkish prime minister (the prime minister of the country had declared on November that neither he nor any one from his family will get the pandemic vaccine). This situation had found an important place the national media [32]. Unjustified fears about the adverse effects of pandemic influenza $\mathrm{A} / \mathrm{H} 1 \mathrm{~N} 1$ vaccine, among $\mathrm{HCW}$ s as well as the public, have certainly been influenced by the mixed messages coming from vaccine-resistant Prime Minister. Media seems to be an important source of information (and sometimes the only information source even among doctors and nurses) about pandemic influenza $\mathrm{A} / \mathrm{H} 1 \mathrm{~N} 1$ in our study population. Media can be accepted as a primary source of information in the general public, but our study group was HCWs and half of them were doctors and nurses. We believe that this finding is needs special investigation because in our opinion evidence based scientific sources and health authorities instead of the media should the primary information source of health care professions.

$\mathrm{HCW}$ s play a critical role in disseminating accurate information about pandemic influenza $\mathrm{A} / \mathrm{H} 1 \mathrm{~N} 1$ vaccine. Besides being the main persons for implementation of pandemic influenza $\mathrm{A} / \mathrm{H} 1 \mathrm{~N} 1$ vaccine, the HCWs and their family members are recipients of the vaccine. Therefore believes and attitudes of HCWs towards pandemic influenza $\mathrm{A} / \mathrm{H} 1 \mathrm{~N} 1$ vaccination, can play an important role in supporting or blocking the vaccination efforts. A negative attitude of a $\mathrm{HCW}$ towards vaccination may grow as a snowball. A negative attitude of a HCW as a parent of a school child or a day care child, towards pandemic influenza vaccination possibly may have negative impact on the decision of the other parents of the classmates and teachers. An online survey conducted by a research company in Turkey, reports that out of 8,600 respondents $95 \%$ had not been vaccinated against pandemic influenza $\mathrm{A} / \mathrm{H} 1 \mathrm{~N} 1$. Eleven percent of negative respondents had consulted a doctor about the vaccine, and therefore argues in the negative opinions and $10 \%$ percent said they were influenced by unfavorable opinion of Prime Minister, who previously said he would not receive the vaccine, in choosing refusing of the vaccine [33].
Our study has some limitations, and the results should be interpreted with these limitations. First limitation is that it covers only one hospital. Another limitation is the lack of details (especially their parental status) for the HCWs that we could not been interviewed (223/ $941,23.6 \%)$ mainly because of the shift work in the hospital. Therefore a selection bias could have occurred. Lack of details about the age of their children and the fact that children could have chronic underlying disease is another important limitation of our study. Self-reporting vaccine uptake of children might be a potential bias also. All these points might limit to generalize our study results. Nevertheless, our study gives important information about HCWs actual attitudes as parents towards vaccinating their children with pandemic influenza $A$ / $\mathrm{H} 1 \mathrm{~N} 1$ vaccine because it was conducted at an advance of pandemic phase.

Despite some limitations, our survey could be a useful tool for decision makers to promote programs and campaigns aimed at informing and educating $\mathrm{HCW}$ as well as parents.

\section{Conclusion}

This study supports that persuading parents to accept a new vaccine seems not be easy even if they are HCWs. In order to overcome the barriers for vaccination among HCWs, determination of their misinformation, attitudes and behaviors regarding the pandemic influenza vaccination seems to be essential. For effectiveness of mass vaccination campaigns coherence between the authorities is important. Efforts for orienting the HCWs (especially doctors and nurses) to use medical and evidence based scientific sources, rather than the media for information related to health should be considered by the authorities. Efforts should be made to inform HCWs regarding the benefits of vaccination and the potential health consequences of influenza illness for their patients, themselves, and their family members.

Educational campaigns concerning the HCWs should include evidence based and comprehensible information about possible adverse effects of the vaccine and their incidence.

\section{Additional material}

Additional file 1: Questionnaire. The questionnaire which was the source of information utilized in this article is shown, translated from Turkish.

\section{Author details}

${ }^{1}$ Assistt Rehberlik ve Müsteri Hizmetleri A.S., Istanbul, Turkey. ${ }^{2}$ Umraniye Research and Training Hospital, Istanbul, Turkey. ${ }^{3}$ Karabük Public Health Center, Turkey. 


\section{Authors' contributions}

SDT designed the study, reviewed the literature, analyzed the data and was responsible for writing the manuscript. FT participated in the coordination of the study, collected and entered the data, helped to literature review. BC helped to draft the manuscript and to interpret the results. All of the authors read and approved the final manuscript.

\section{Competing interests}

The authors declare that they have no competing interests.

Received: 2 March 2010 Accepted: 10 October 2010 Published: 10 October 2010

\section{References}

1. Novel Swine-Origin Influenza A (H1N1) Virus Investigation Team: Emergence of a novel swine-origin influenza $A(\mathrm{H} 1 \mathrm{~N} 1)$ virus in humans. N Engl J Med 2009, 360:2605-15, [Erratum, N Engl J Med 2009; 361:102.]

2. Fraser C, Donnelly CA, Cauchemez S, Hanage WP, Van Kerkhove MD, Hollingsworth TD, Griffin J, Baggaley RF, Jenkins HE, Lyons EJ, Jombart T, Hinsley WR, Grassly NC, Balloux F, Ghani AC, Ferguson NM, Andrew Rambaut A, Gatell HL, Celia M, et al: Pandemic potential of a strain of influenza A (H1N1): early findings. Science 2009, 324(5934):1557-1561.

3. Yang Y, Sugimoto JD, Halloran ME, Basta NE, Chao DL, Matrajt L, Potter G, Kenah $E$, Longini IM: The transmissibility and control of pandemic influenza A (H1N1) virus. Science 2009, 326(5953):729-733.

4. Cauchemez S, Donnelly CA, Reed C, Ghani AC, Fraser C, Kent CK, Finelli L, Ferguson NM: Household transmission of 2009 pandemic influenza A (H1N1) virus in the United States. N Engl J Med 2009, 361:2619-2627.

5. Ciblak MA, Albayrak N, Odabas Y, Altas AB, Kanturvardar A, Hasoksuz M, Sucakli B, Korukluoglu G, Bal E, Ertek M, Badur S: Cases of influenza A (H1N1)v reported in Turkey, May-July 2009. Euro Surveill 2009, 14(32) [http://www.eurosurveillance.org/ViewArticle.aspx?Articleld=19304], pii=19304.

6. Glass LM, Glass RJ: Social contact networks for the spread of pandemic influenza in children and teenagers. BMC Public Health 2008, 8:61.

7. Centers for Disease Control and Prevention (CDC): Swine-origin influenza $\mathrm{A}(\mathrm{H} 1 \mathrm{~N} 1)$ virus infections in a school - New York City, April 2009. MMWR Morb Mortal Wkly Rep 2009, 58(17):470-472.

8. Smith A, Coles S, Johnson S, Saldana L, Ihekweazu C, O'Moore E: An outbreak of influenza $A(\mathrm{H} 1 \mathrm{~N} 1) v$ in a boarding school in South East England, May-June 2009. Euro Surveill 2009, 14(27):pii 19263 [http://www. eurosurveillance.org/NiewArticle.aspx?Articleld=19263].

9. Guinard A, Grout L, Durand C, Schwoebel V: Outbreak of influenza A (H1N1)v without travel history in a school in the Toulouse district, France, June 2009. Euro Surveill 2009, 14(27):pii:19265 [http://www. eurosurveillance.org/NiewArticle.aspx?Articleld=19265].

10. Salgado CD, Farr BM, Hall KK, Hayden FG: Influenza in the acute hospital setting. Lancet 2002, 2(3):145-155.

11. Carman WF, Elder AG, Wallace LA, et al: Effects of influenza vaccination of health-care workers on mortality of elderly people in long-term care: a randomised controlled trial. Lancet 2000, 355(9198):93-7.

12. Wilde JA, MCMillan JA, Serwint J, Butta J, O'Riordan MA, Steinhoff MC: Effectiveness of influenza vaccine in health care professionals: a randomized trial. JAMA 1999, 281(10):908-13.

13. Fox JP, Hall CE, Cooney MK, Foy HM: Influenza virus infections in Seattle families, 1975-1979. Am J Epidemiol 1982, 116:212-227.

14. Michiels B, Philips H, Coenen S, Yane F, Steinhauser T, Stuyck S, Denekens J, Van Royen P: The effect of giving influenza vaccination to general practitioners: a controlled trial [NCT00221676]. BMC Med 2006, 10(4):17.

15. Hurwitz ES, Haber M, Chang A, Shope T, Teo S, Ginsberg M, Waecker N, Cox NJ: Effectiveness of influenza vaccination of day care children in reducing influenza-related morbidity among household contacts. JAMA 2000, 284:1677-1682.

16. Reichert TA, Sugaya N, Fedson DS, Glezen WP, Simonsen L, Tashiro M: The Japanese experience with vaccinating schoolchildren against influenza. N Engl JMed 2001, 344:889-896.

17. Viboud C, Boëlle P, Cauchemez S, Lavenu A, Valleron A, Antoine Flahault, Carrat F: Risk factors of influenza transmission in households. $\mathrm{Br} J \mathrm{Gen}$ Pract 2004, 54:684-689.

18. European Centre for Disease Prevention and Control Guide to public health measures to reduce the impact of influenza pandemics in
Europe - 'The ECDC Menu'. ECDC September 2009. [http://ecdc.europa. eu/en/publications/Publications/

0906_TER_Public_Health_Measures_for_Influenza_Pandemics.pdf].

19. World Health Organization: WHO recommendations on pandemic (H1N1) 2009 vaccines. Pandemic (H1N1) 2009 briefing note 2. [http://www.who. int/csr/disease/swineflu/notes/h1n1_vaccine_20090713/en/index.html], Accessed 13 June 2010.

20. WHO Pandemic influenza preparedness and response. WHO guidance document April 2009. [http://www.who.int/csr/disease/influenza/ pipguidance2009/en/index.html], Accessed 18 June 2010.

21. Vírseda S, Restrepo MA, Arranz E, Magán-Tapia P, Fernández-Ruiz M, de la Cámara AG, Aguado JM, López-Medrano F: Seasonal and Pandemic A (H1N1) 2009 influenza vaccination coverage and attitudes among health-care workers in a Spanish University Hospital. Vaccine 2010, 28(30):4751-7.

22. La Torre G, Di Thiene D, Cadeddu C, Ricciardi W, Boccia A: Behaviours regarding preventive measures against pandemic $\mathrm{H} 1 \mathrm{~N} 1$ influenza among Italian healthcare workers, October 2009. Euro Surveill 2009, 14(49) [http://www.eurosurveillance.org/NiewArticle.aspx?Articleld=19432], pii=19432.

23. Rachiotis G, Mouchtouri VA, Kremastinou J, Gourgoulianis K, Hadjichristodoulou C: Low acceptance of vaccination against the 2009 pandemic influenza $\mathrm{A}(\mathrm{H} 1 \mathrm{~N} 1)$ among healthcare workers in Greece. Euro Surveill 2010, 15(6):pii=19432 [http://www.eurosurveillance.org/ViewArticle. aspx?Articleld=19486].

24. Torun SD, Torun F: Vaccination against pandemic influenza A/H1N1 among healthcare workers and reasons for refusing vaccination in Istanbul in last pandemic alert phase. Vaccine 2010.

25. Turkish Ministry of Health: Dünyada ve ülkemizde H1N1 pandemisinin seyri (Progress of H1N1 pandemic in the world and Turkey). [http://www. grip.gov.tr/images/stories/basin/05_ocakbulten.pdf], Accessed 13 June 2010.

26. Turkish Ministry of Health: [http://www.saglik.gov.tr/TR/Genel/BelgeGoster. aspx?F6E10F8892433CFFA91171E62F0FF153C33ECC96EA79FF5C], Accessed 13 June 2010.

27. Turkish Ministry of Health: [http://www.grip.gov.tr/index.php? option=com_content\&view=article\&id=672:03kasim\&c], Accessed 13 June 2010.

28. Turkish Society of Clinical Pharmacology. [http://www.kfd.org.tr/?q=node/ 641], Accessed 22 July 2010.

29. Turkish Medical Association: [http://www.ttb.org.tr/mevzuat/index.php? option=com_content\&task=view\&id=645\&ltemid = 33], Accessed 22 July 2010.

30. Tozzi AE, Gesualdo F, Romano M, Caione D: Parental attitude toward influenza A(H1N1)v vaccination in Italy. Vaccine 2009, 27(49):6807.

31. Hak E: Negative attitude of highly educated parents and health care workers towards future vaccinations in the Dutch childhood vaccination program. Vaccine 2005, 23(24):3103-3107.

32. As pandemics picks up speed, Turks still confused on vaccine. [http:// www.hurriyetdailynews.com/n.php?n=pandemic-picks-up-speed-turks-stillconfused-on-vaccine-2009-11-23], Accessed 23 July 2010.

33. "Swine Flu in 50 Questions". Herkese Sağlik (Health for All) November 2009: 1. Print.

\section{Pre-publication history}

The pre-publication history for this paper can be accessed here: http://www.biomedcentral.com/1471-2458/10/596/prepub

\section{doi:10.1186/1471-2458-10-596}

Cite this article as: Torun et al:: Healthcare workers as parents: attitudes toward vaccinating their children against pandemic influenza $A / H 1 N 1$. BMC Public Health 2010 10:596. 